\title{
Partitioning of food resources in bathypelagic micronekton in the eastern Gulf of Mexico
}

\author{
Scott E. Burghart* ${ }^{*}$ Thomas L. Hopkins, José J. Torres \\ University of South Florida College of Marine Science, 140 7th Avenue South, St. Petersburg, Florida 33701, USA
}

\begin{abstract}
A mid-water trawl survey conducted between depths of 1000 and $3000 \mathrm{~m}$ in the eastern Gulf of Mexico found $54 \%$ of the organisms collected were gonostomatid fishes. Lophogastrids within the family Eucopiidae were also common $(17.3 \%)$, as were decapod shrimps within the families Oplophoridae and Benthesicymidae (9.9 and $7.1 \%$ respectively). We examined the gut contents of 14 prominent species from this assemblage to determine if available food resources were partitioned. Cluster analysis of stomach contents resulted in 4 clusters based on taxonomic composition and 3 based on prey size. Bristlemouth fishes (Gonostomatidae) of the genus Cyclothone and lophogastrids of the genus Eucopia were planktivorous, consuming smaller prey items such as copepods and ostracods. Decapods within the family Oplophoridae tended to be piscivorous and consumed relatively large prey. Dendrobranchiate shrimps appeared to regularly consume detrital material, although the contribution of such material to the overall diet could not be quantified. The hatchetfish Sternoptyx pseudobscura had a large proportion of shallow-living taxa in its diet despite being non-migratory. Many of the bathypelagic species were found to be more piscivorous than mesopelagic counterparts within the same family or genus. Dietary overlap in both prey size and taxonomic composition was rare, occurring only $16.5 \%$ of the time. The most prevalent pattern ( $50 \%$ of species pairings) was overlap in neither diet category, suggesting the species partitioned food resources.
\end{abstract}

KEY WORDS: Bathypelagic zone $\cdot$ Micronekton $\cdot$ Diet $\cdot$ Niche $\cdot$ Resource partitioning

\section{INTRODUCTION}

Beginning with Hutchinson (1961), oceanic ecologists have been asking how high diversity is maintained in pelagic environments. Past investigations in the eastern Gulf of Mexico (EGOM) clearly demonstrated niche partitioning among confamilials (Flock \& Hopkins 1992, Hopkins \& Gartner 1992, Kinsey \& Hopkins 1994, Sutton \& Hopkins 1996a) as well as between species within a taxonomically diverse assemblage (Hopkins et al. 1994, Hopkins \& Sutton 1998). However, these studies were limited to organisms residing within the epipelagic and mesopelagic zones of the ocean. While such environments are considered structurally simple relative to many other marine ecosystems (e.g. rocky intertidal or estuarine), there are strong vertical gradients in light, temperature, pressure, and biomass. The bathypelagic zone (depth
$>1000 \mathrm{~m}$ ) contains no significant gradients in sunlight and temperature, creating a further reduction in habitat structure.

This study is based on a trawling program that targeted the bathypelagic zone in the EGOM, a region with biological and physical features typical of low latitude oceanic environments (Hopkins \& Gartner 1992, Hopkins et al. 1994). Furthermore, most of the crustaceans in this environment have pan-tropical distributions (Burghart et al. 2007), suggesting a wide applicability of the results. Deep-sea diet studies focusing on depths $>1000 \mathrm{~m}$ are uncommon, usually restricted to a few species within the same taxonomic subset of the community (e.g. fishes or shrimp), and often deal with benthic or benthopelagic species (e.g. Mauchline \& Gordon 1985, 1986, Cartes 1993a,b, 1998, Blankenship \& Levin 2007, Fanelli et al. 2009). We consider competition between diverse taxa residing in the pelagic 
zone between $1000 \mathrm{~m}$ and the bottom $(\sim 3000 \mathrm{~m})$. The goals of this study were to describe the diets of bathypelagic species, identify trophic guilds, and examine if resource partitioning can be resolved using only prey size and diet composition as niche parameters. To investigate, we examined the diets of 14 of the most prominent members of this community.

\section{MATERIALS AND METHODS}

Organisms used in diet analysis came from a series of discrete-depth samples collected within a $30 \mathrm{~km}$ radius of $27^{\circ} \mathrm{N}, 86^{\circ} \mathrm{W}$. The trawl used was an opening/ closing rectangular midwater trawl with a $9 \mathrm{~m}^{2}$ mouth area. Depth of the net was monitored on deck, which allowed the water column to be divided into discrete depth zones for sampling (Table 1). The net itself had a $4 \mathrm{~mm}$ mesh which tapered back to a $1 \mathrm{~m}$ diameter ring net and a closed cod end with $1 \mathrm{~mm}$ mesh. The sampling procedure is described in more detail by Burghart et al. (2007).

The data from crustaceans and fish were combined for the purpose of presenting an overview of the dominant components of the bathypelagic micronektonic assemblage, where we considered micronekton to be organisms captured by the sampling gear with a total length $>20 \mathrm{~mm}$. Species numbers were converted to biomass using relationships between total or standard length and weight established from mesopelagic samples. Whenever possible, regressions were generated using data obtained from non-preserved material (J. J. Torres \& J. Donnelly unpubl.). For some species, it was necessary to weigh and measure preserved material. In such cases, measurements were adjusted upward by $12 \%$ for length (unless the length measure depended entirely on hard parts such as the carapace) and $20 \%$ for weight (Gartner et al. 1988). Dry weights were calculated by adjusting for water content reported for the closest possible taxonomic group (Childress \& Nygaard 1973, 1974, Donnelly \& Torres 1988, Stickney \& Torres 1989, Childress et al. 1990, Sutton \& Hopkins 1996b, J.J. Torres \& J. Donnelly unpubl.). At times it

Table 1. Depth distribution of trawl samples. The category 'Other' refers to trawls that were deeper than $1000 \mathrm{~m}$ but did not fit into one of the 3 depth categories (e.g. 1000-2000 m)

\begin{tabular}{|lc|}
\hline Depth $(\mathrm{m})$ & Number of tows \\
\hline $1000-1500$ & 20 \\
$1500-2000$ & 16 \\
$>2000$ & 7 \\
Other & 3 \\
Total & 46 \\
\hline
\end{tabular}

was necessary to apply a single equation to multiple genera; in such cases, phylogeny and morphology were matched as closely as possible.

Animals used in diet analysis were measured to the nearest $1 \mathrm{~mm}$ before removal of their digestive tracts. The entire tract was removed from fishes and the entire foregut and midgut was excised from shrimps, as was the posterior portion of the intestine through to at least abdominal segment 3 . Contents of the digestive tracts were spread out on glass slides in glycerol, and then examined on an Olympus BX60 compound scope equipped with Nomarski DIC optics at $\times 40-600$ magnifications. Prey items recovered from stomachs and intestines were recorded separately. When possible, individuals from a species were dissected until a curve of prey taxa versus the number of individuals analyzed became asymptotic. This was taken as an indication that analysis adequately represented prey taxonomic richness. Due to the low number of individuals available for dissection, this was not possible for Acanthephyra acutifrons and Notostomus gibbosus (Table 2).

Diet items were identified to the lowest possible taxonomic level, and measured whenever possible. The presence of some material other than scales, such as bone or eye lenses, was required for a positive occurrence of fish to be recorded. Occurrence of entire prey items within the digestive tract of shrimp was rare, and a portion of the prey item resistant to digestion generally had to be measured. In such cases, relationships between size of the body part and the overall size of the prey species (T. L. Hopkins \& S. E. Burghart unpubl. data) were applied to obtain a prey size. In cases where taxon-specific relationships were unavailable, an analogous relationship from the closest possible taxon of similar morphology was applied. For some organisms, such as some polychaetes, size relationships could not be established. In those instances, prey size was based on an average size of the organism in the environment (T. L. Hopkins unpubl.). In cases for which positive prey identifications were possible without the presence of any measurable body part, the average size of the same prey from within the same species/size predator group was used. After assigning a size to every possible prey item, they were placed into 1 of 18 size categories for cluster analysis: $1 \mathrm{~mm}$ increments up to $10 \mathrm{~mm}, 2 \mathrm{~mm}$ increments up to $20 \mathrm{~mm}, 5 \mathrm{~mm}$ increments up to $30 \mathrm{~mm}$, and 1 group $>30 \mathrm{~mm}$. The presence of detritus and nematocysts was often recorded but could not be measured in a form convertible to size or biomass.

After establishing or estimating a size for all possible prey items, regressions were used to convert prey size to biomass (T. L. Hopkins \& S. E. Burghart unpubl. data). In many cases, these were the same equations used to 


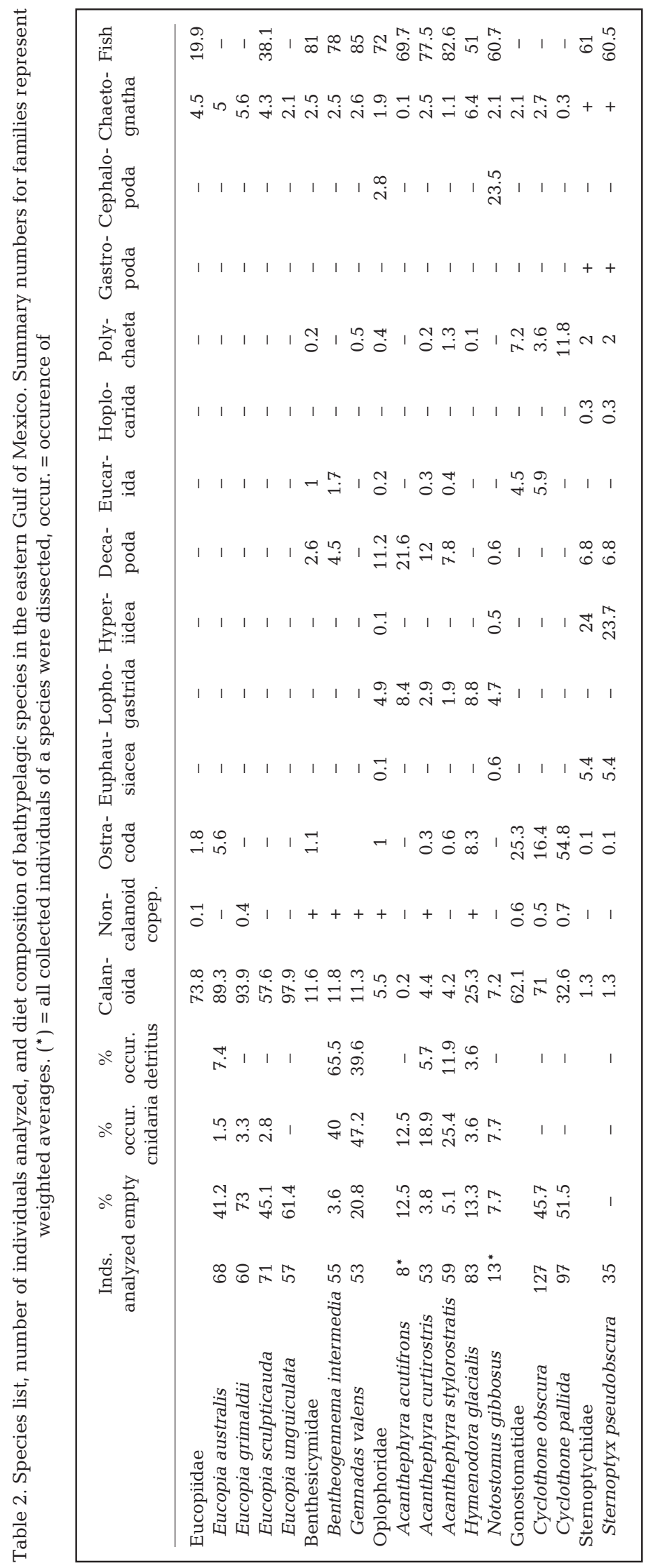

establish organism dry weight from the trawl samples. Diet taxa were grouped into 13 broad categories: calanoid copepods, cephalopods, chaetognaths, decapods, euphausiids, fish, gastropods, hyperiids, lophogastrids, miscellaneous crustaceans, non-calanoid copepods, ostracods, and polychaetes. Results, in terms of prey size and taxonomic composition, were square root transformed and run through cluster analysis and multidimensional scaling (MDS) in Primer 6 (version 6.1.12, Primer E) using the Bray-Curtis index. The similarity profile test (SIMPROF) was applied to objectively determine valid clusters at p $<0.05$ (Clarke \& Gorley 2006, Clarke et al. 2008).

\section{RESULTS}

\section{Overall community structure}

Gonostomatids (bristlemouth fishes) accounted for $54.1 \%$ of the organisms captured, and 7 other families accounted for at least $1 \%$ : the lophogastrid family Eucopiidae (17.3\%), the caridean decapod family Oplophoridae (9.9\%), the dendrobranchiate decapod families Benthesicymidae $(7.1 \%)$ and Sergestidae $(2.6 \%)$, lanternfishes (Myctophidae, 2.5\%), hatchetfishes (Sternoptychidae, $1.8 \%$ ), and bigscale fishes (Melamphaidae, $1 \%$ ). While fishes accounted for $62.2 \%$ of the numbers of organisms collected, $56 \%$ of the estimated biomass was attributed to crustaceans. A total of 8 families accounted for at least $2 \%$ of the total estimated biomass: Oplophoridae (33.2\%), Gonostomatidae (18.7\%), Nemichthyidae (snipe eels, 10.6\%), Benthesicymidae $(10.0 \%)$, Eucopiidae (7.3\%), Myctophidae $(5.5 \%)$, Sergestidae (3.4\%), and Sternoptychidae $(2.2 \%)$. Community analysis of the samples suggested that the depth zones did not represent distinct communities within the bathypelagic zone (S. E. Burghart unpubl. data), and we thus worked under the assumption that all organisms belonged to the same community.

\section{Diet}

Diet analysis was performed on 850 specimens from 14 species belonging to 5 prominent families: Oplophoridae, Benthesicymidae, Eucopiidae, Sternoptychidae, and Gonostomatidae. The species were chosen based on their relative abundance and estimated biomass in the community. Together they represented $78.6 \%$ of the 
Table 3. Relative importance of species included in diet analysis within the overall assemblage in terms of abundance and estimated biomass. Species abbreviations used in cluster diagrams are listed in the key column

\begin{tabular}{|c|c|c|c|c|c|c|c|}
\hline Order & Family & Species & Key & $\begin{array}{l}\text { Abund. } \\
\text { rank }\end{array}$ & $\begin{array}{l}\text { Abund. } \\
(\%)\end{array}$ & $\begin{array}{l}\text { Biomass } \\
\text { rank }\end{array}$ & $\begin{array}{c}\text { Estim. } \\
\text { biomass }(\%)\end{array}$ \\
\hline Stomiiformes & Gonostomatidae & Cyclothone pallida (Brauer, 1902) & Cpall & 1 & 24.9 & 5 & 6.1 \\
\hline Stomiiformes & Gonostomatidae & Cyclothone obscura (Brauer, 1902) & Cobsra & 2 & 22.6 & 1 & 11.0 \\
\hline Lophogastrida & Eucopiidae & Eucopia sculpticauda (Faxon, 1893) & Esclp & 3 & 4.8 & 16 & 1.5 \\
\hline Lophogastrida & Eucopiidae & Eucopia australis (Dana, 1852) & Eaust & 4 & 4.8 & 9 & 2.9 \\
\hline Lophogastrida & Eucopiidae & Eucopia grimaldii (Nouvel, 1942) & Egrim & 5 & 4.6 & 15 & 1.8 \\
\hline Decapoda & Benthesicymidae & Bentheogennema intermedia (Bate, 1888) & Binter & 6 & 3.1 & 4 & 7.0 \\
\hline Decapoda & Oplophoridae & Hymenodora glacialis (Buchholz, 1874) & Hglac & 7 & 3.1 & 11 & 2.3 \\
\hline Lophogastrida & Eucopiidae & Eucopia unguiculata (Willemoes-Suhm, 1875) & Eungc & 8 & 3.0 & 18 & 1.1 \\
\hline Decapoda & Oplophoridae & Acanthephyra stylorostratis (Bate, 1888) & Astylo & 9 & 2.9 & 8 & 3.1 \\
\hline Decapoda & Benthesicymidae & Gennadas valens (S. I. Smith, 1884) & Gvlns & 10 & 2.3 & 12 & 1.9 \\
\hline Stomiiformes & Sternoptychidae & Sternoptyx pseudobscura (Baird, 1971) & Spsud & 14 & 1.3 & 14 & 1.8 \\
\hline Decapoda & Oplophoridae & Acanthephyra curtirostris (Wood-Mason, 1891) & Acurt & 16 & 1.0 & 7 & 3.2 \\
\hline Decapoda & Oplophoridae & Notostomus gibbosus (A. Milne-Edwards, 1881) & Ngibb & 38 & 0.1 & 6 & 6.1 \\
\hline \multirow[t]{2}{*}{ Decapoda } & Oplophoridae & Acanthephyra acutifrons (Bate, 1888) & Aacut & 54 & 0.1 & 3 & 8.7 \\
\hline & & Sum & & & 78.6 & & 58.5 \\
\hline
\end{tabular}

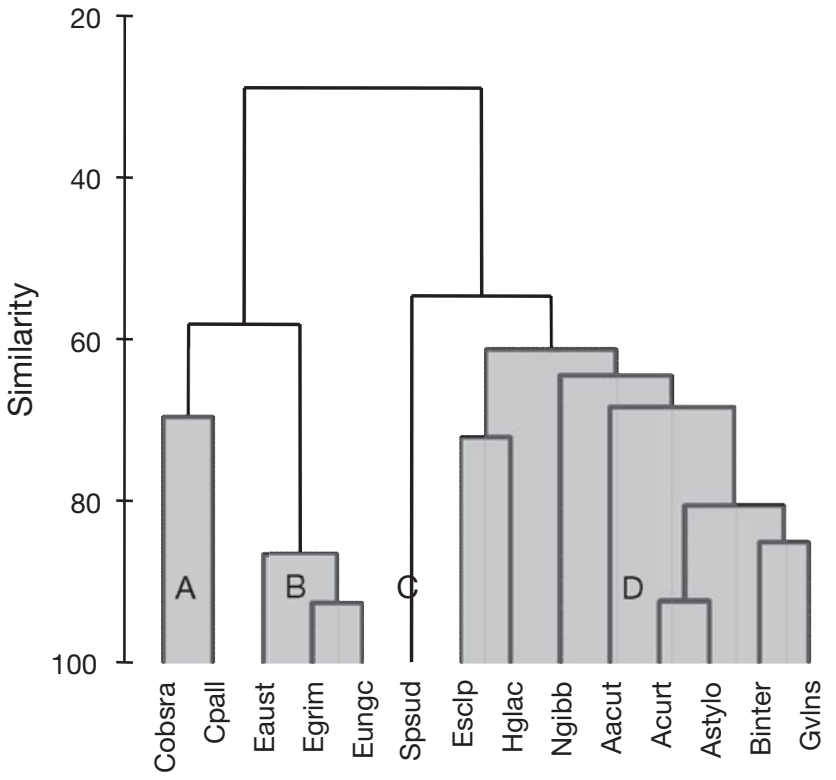

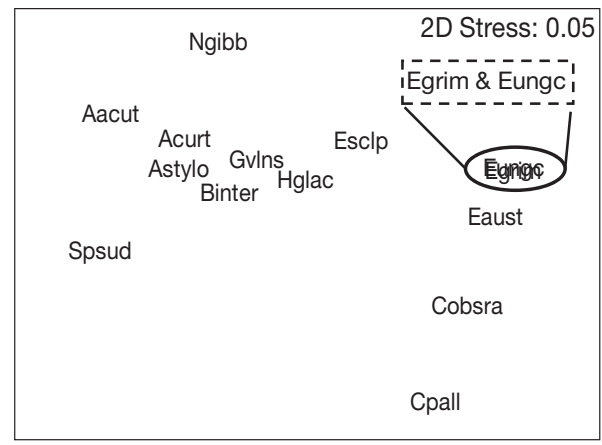

Fig. 1. Cluster diagram and MDS plot of diet biomass for 14 species of bathypelagic micronekton based on Bray-Curtis similarity. Species groupings were determined by a SIMPROF test $(p<0.05)$. The species key can be found in Table 3 numerically and $58.5 \%$ of the community biomass (Table 3), while their respective families represented $90.2 \%$ numerically and $71.4 \%$ of the biomass. More crustacean species were analyzed because, other than the Gonostomatidae, most fish species were large but rare (Burghart 2006). The Nemichthyidae, one of the more important families in terms of biomass, was represented only by the snipe eel Avocettina infans. Although uncommon, individuals were large enough to have the species rank second in terms of biomass. Unfortunately, damage to the few specimens captured precluded inclusion of this important family in the diet study.
The proportion of empty digestive tracts varied widely between species. A low frequency of empty guts $(<10 \%)$ were found in Sternoptyx pseudobscura $(0 \%)$, Acanthephyra curtirostris $(3.8 \%)$, A. stylorostratis $(5.1 \%)$, Notostomus gibbosus (7.7\%) and Bentheogennema intermedia (3.6\%), while high proportions were found in 2 species of Eucopia: E. grimaldii (73\%) and E. unguiculata (61\%). Four species contained no food about half of the time: Cyclothone obscura (46\%), C. pallida (52\%), E. australis (41\%), and E. sculpticauda $(45 \%)$, while the 3 remaining species, Gennadas valens, Hymenodora glacialis, and A. acutifrons, were empty $21 \%, 13 \%$, and $13 \%$ of the time, respectively. 


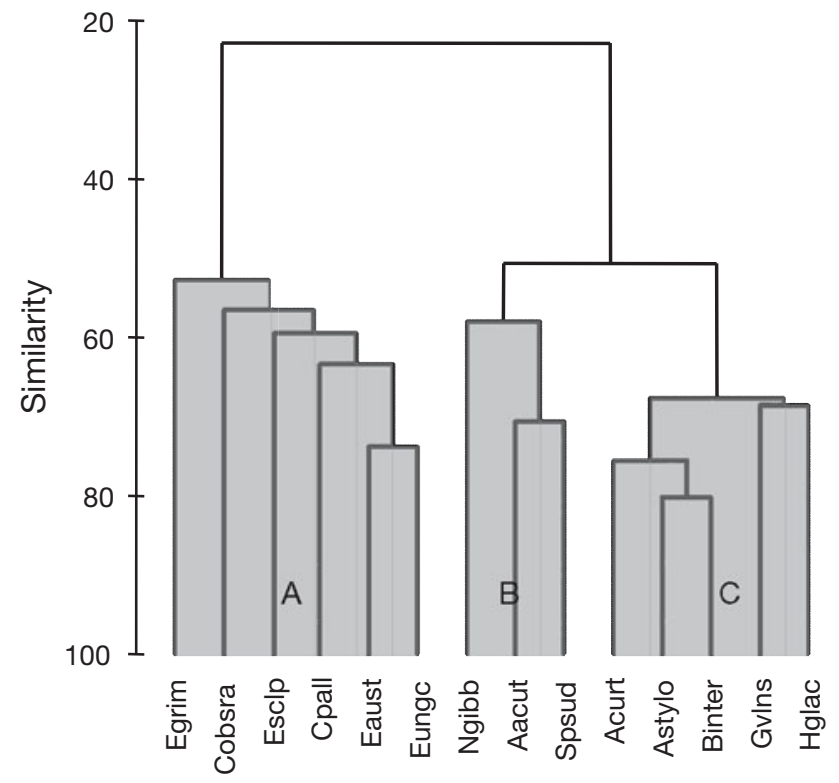

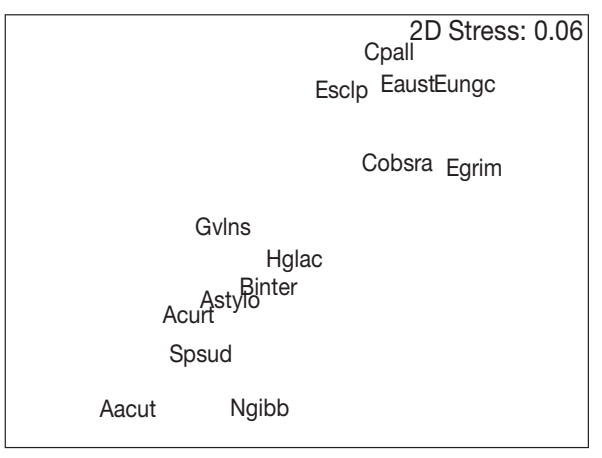

Fig. 2. Cluster diagram and MDS plot for prey size of 14 species of bathypelagic micronekton according to Bray-Curtis dissimilarity. Species groupings were determined by a SIMPROF test $(p<0.05)$. The species key can be found in Table 3
As mentioned in 'Materials and methods', it was not possible to estimate biomass of detrital or cnidarian materials in digestive tracts, although their occurrence suggested they were important dietary components in some species. Cnidarian material, usually in the form of nematocysts, occurred in at least $40 \%$ of individuals of Bentheogennema intermedia and Gennadas valens. It was less common in Acanthephyra stylorostratis $(25.4 \%), A$. curtirostris $(18.9 \%)$, and A. acutifrons $(12.5 \%)$. All remaining species had less than a $10 \%$ occurrence of nematocysts. Detrital material was prevalent in $B$. intermedia, occurring in $65.5 \%$ of individuals examined, and common in G. valens ( $40 \%$ of individuals). A. stylorostratis was the only other species in which detritus appeared in more than $10 \%$ of the individuals $(11.9 \%)$, and 8 of the species examined showed no evidence of such material.

Cluster analysis of diet composition based on biomass resulted in 4 feeding clusters according to the SIMPROF test (Fig. 1). Cluster A included both species of Cyclothone examined; it was characterized by a diet consisting of small planktonic crustaceans, specifically calanoid copepods and ostracods, which made up 62 and $25 \%$ respectively of their combined diet. Other diet taxa included polychaetes $(7.2 \%)$, miscellaneous crustaceans $(4.5 \%)$, chaetognaths $(2.1 \%)$, and noncalanoid copepods $(<1 \%)$. Cluster B, which contained 3 of the 4 species of Eucopia, was characterized by a copepod dietary fraction of $91.5 \%$. Other prey categories included chaetognaths $(4.7 \%)$, ostracods $(3.7 \%)$ and non-calanoid copepods $(<1 \%)$.

Fish contributed most to the prey biomass of predators in clusters C and D. Cluster C contained only Sternoptyx pseudobscura, which preyed upon 10 different diet categories, the most prominent being fish which made up $60 \%$ of the diet. Hyperiid amphipods contributed the second highest diet percentage $(24 \%)$, followed by decapods (6.8\%) and euphausiids (5.4\%). All other categories contributed less than $5 \%$. Cluster D contained the most species and, except for the lophogastrid Eucopia sculpticauda, was composed entirely of decapods. Together, species within the cluster consumed 12 of the 13 prey categories, though fish made up $73.7 \%$ of the diet. Only 2 other categories accounted for more than $5 \%$ of the diet: decapods $(9.3 \%)$ and calanoid copepods $(7.2 \%)$.

Cluster analysis for prey size resulted in 3 clusters (Fig. 2). Species in cluster A included both of the bristlemouth fishes, Cyclothone obscura and C. pallida, as well as the 4 lophogastrid shrimps of the genus Eucopia. Diets within the cluster were characterized mainly by small prey items $(<10 \mathrm{~mm})$, with $87.4 \%$ of the biomass distributed below the 10 to $11.9 \mathrm{~mm}$ size bin (Fig. 3).

The remaining clusters (B and C) contained species whose prey biomass was primarily derived from items larger than $10 \mathrm{~mm}$. Species within cluster B (the decapods Acanthephyra acutifrons and Notostomus gibbosus, and the hatchetfish Sternoptyx pseudobscura) took the largest prey items (Fig. 3). The mode of their prey size was in the largest possible category (>30 $\mathrm{mm}$ ) and accounted for $34.1 \%$ of their prey biomass. Finally, the 5 decapods making up Cluster $\mathrm{C}$ had prey lengths primarily between 14 and $19.9 \mathrm{~mm}$ (Fig. 3). 


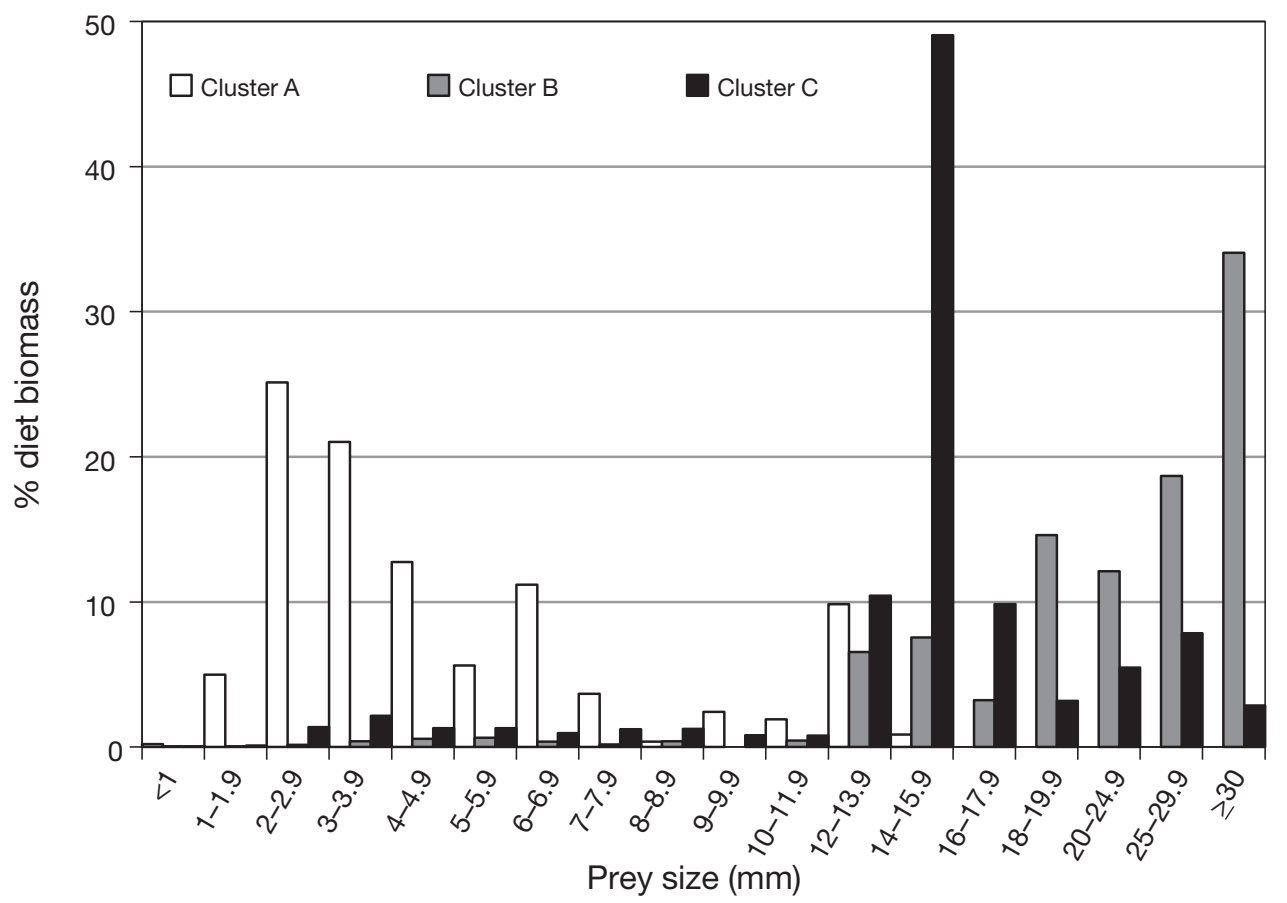

Fig. 3. Prey size bin distributions for the 3 prey size clusters

\section{DISCUSSION}

\section{Net feeding}

Of major concern in diet analysis is sample contamination due to net feeding. We felt the data were not impacted by net feeding for 2 reasons. (1) Dietary differences were evident between species. To invoke diet differences under conditions of net feeding one must assume different groups are feeding selectively and distinctively within the cod end. For example, hyperiid remains were recovered in only 2 species: Notostomus gibbosus (only 1 occasion), and Sternoptyx pseudobscura $(74 \%$ of individuals examined). To obtain this result under conditions of significant net feeding would require that $S$. pseudobscura consume hyperiids within the cod end while all other species ignore them. (2) Material recorded from the stomachs and intestines of each species was similar. In $85 \%$ of the species, the most numerous diet categories found in both the stomachs and intestines were identical. Further, in $75 \%$ of the cases, each section of the digestive tract had 2 of the top 3 diet categories in common. In some cases, a significant number of the diet items recorded were found in the intestine, suggesting the animals had not fed for some time. The most extreme examples of this were found in Cyclothone pallida and Eucopia unguiculata, for which $\sim 80 \%$ of the items recorded were found in the intestine. Similarly, the other 3 species of
Eucopia as well as C. obscura had $\sim 50 \%$ or more of their diet items contained in the intestine.

\section{Problematic diet categories}

We were not able to estimate the biomass contribution due to detritus and cnidaria, preventing inclusion of these diet categories in the cluster analysis. Such material may be important, and detritus has even been suggested as a primary carbon source in some systems (Polunin et al. 2001). Although the occurrence of those categories was relatively minor in most species here (Table 2), it was likely prominent enough to hinder resolving interspecies diet differences in some cases.

Three species within the Oplophoridae contained cnidarian material more than $10 \%$ of the time: Acanthephyra acutifrons $(12.5 \%)$, A. curtirostris $(18.9 \%)$, and A. stylorostratis (25.4\%). Additionally, A. stylorostratis contained detritus in $11.9 \%$ of the individuals examined. The inability to quantify cnidarian or detrital material was most important in the cases of Bentheogennema intermedia and Gennadas valens, the latter of which has previously been shown to graze heavily on marine snow (Heffernan \& Hopkins 1981). Both cnidarian material and detritus appeared to be significant for both of those shrimp species (Table 2), suggesting habitual consumption. In particular, the high occurrence of detritus in the diet of $B$. intermedia 
$(65.5 \%)$ had the potential to enhance the distinction of the diet of this species, as only calanoid copepods appeared more frequently ( $74.5 \%$ of the individuals).

\section{Diet composition}

Cluster results for diet composition generally fell along phylogenetic lines. Cluster A contained both species of gonostomatids, Cluster B contained 3 of the 4 species of lophogastrids, Cluster C contained the sternoptychid, and Cluster D primarily contained decapods (Fig. 1). Eucopia sculpticauda proved to be an exception by appearing in Cluster D among the decapods. This was due to the consumption of 1 fish by a single individual and resulted in the diet of E. sculpticauda most closely resembling that of Hymenodora glacialis, the smallest of the decapods examined and the one with the smallest proportion of fish in its diet. Roe (1984) found the diet of E. unguiculata was numerically dominated by copepods, and fish material was not reported. However, the appearance of fish in the diets of E. australis and E. unguiculata is documented (Hopkins et al. 1994), and it thus appears that members of the genus feed primarily on calanoid copepods, occasionally supplementing with fish.

A prominent feature of both the prey biomass and prey size analyses was the clear split creating 2 supergroups in each dendrogram (Figs. 1 \& 2). Again, Eucopia sculpticauda was exceptional in that it switched from one super-group to the other. While the phylogenetic trend in prey size was not as clear as in diet composition, no other species switched supergroups, indicating that the Gonostomatidae and Eucopiidae preyed primarily on small crustaceans. The Oplophoridae, Sternoptychidae and Benthesicymidae had diverse diets, but consumed larger prey items and were primarily piscivorous.

Prey size cluster results may have been related to the size of the predators since Cluster B contained the 2 largest decapod species and the largest fish species examined. Predators in prey size Cluster $\mathrm{C}$ were also generally larger than those in Cluster A, although the decapod Hymenodora glacialis had the shortest mean length of any species examined (27.7 mm TL).

Also prominent was the greater reliance on fish by decapods in the bathypelagic zone relative to the mesopelagic zone. Cartes (1993b) found the diet of Acanthephyra pelagica, collected near the bottom at depths ranging from 640 to $1254 \mathrm{~m}$, consisted mainly of fish, with other common diet groups including pteropods, decapods, and siphonophores. This diet composition is similar to confamilials examined in this study. Hopkins et al. (1994) found the average size of fish eaten in their samples was $12 \mathrm{~mm}$ and subsequently inserted the dry weight equivalent of a $12 \mathrm{~mm}$ Cyclothone for all records of fish in the gut contents. In the present study, fish biomass was estimated for each individual occurrence. While the methods used to estimate prey biomass were slightly different, the major portion of the increase likely resulted from the size difference of the prey given that the average length of fish consumed in this study was $18 \mathrm{~mm}$.

A comparison with mesopelagic data at the same location (Hopkins et al. 1994) suggests much of the difference was due to the replacement of chaetognath and euphausiid biomass with fish (Table 4). In both cases, the reduction in biomass attributed to chaetognaths and euphausiids almost exactly equaled the percentage increase attributed to fish. This is perhaps unsurprising given the results of Hopkins (1982) and Kinsey \& Hopkins (1994) in which chaetognaths and the euphausiid genus Stylocheiron resided primarily in the upper mesopelagic to epipelagic zones. Biomass contributions to diet from all other groups remained similar in Table 2, excepting the percentage of 'other' in the diets of Benthesicymidae. The difference here resulted from the contribution of radiolarians in the mesopelagic study (9.7\%), a group not encountered in great numbers in this study, but a likely byproduct of marine snow consumption. Reliance on such material as a diet component was also noted within this group below $1000 \mathrm{~m}$. It thus appears the reduced presence of some prey groups in the bathypelagic zone was offset by increased consumption of fish by bathypelagic decapods relative to their mesopelagic counterparts.

The diet composition of Sternoptyx pseudobscura proved enigmatic as in other studies. Other than an increase in the proportion of fish consumed, these results were similar to previous data (Hopkins \& Baird 1985, Kinzer \& Schulz 1988). While $61 \%$ of the con-

Table 4. Comparison of the dietary contribution of prey categories between mesopelagic and bathypelagic predators in 2 families of decapods. Mesopelagic values are taken from Hopkins et al. (1994)

\begin{tabular}{|lcccc|}
\hline & \multicolumn{2}{c}{ Benthesicymidae } & \multicolumn{2}{c|}{ Oplophoridae } \\
& Mesopelagic & Bathypelagic & Mesopelagic Bathypelagic \\
\hline Calanoida & 13.3 & 11.6 & 6.7 & 5.5 \\
Cephalopoda & 0 & 0 & 4.1 & 2.8 \\
Chaetognatha & 13.3 & 2.5 & 23.3 & 1.9 \\
Decapoda & 0 & 2.6 & 9 & 11.2 \\
Euphausiacea & 27.3 & 0 & 17.9 & 0.1 \\
Fish & 31.7 & 81 & 33.2 & 72 \\
Ostracoda & 0 & 1.1 & 0 & 1 \\
Other & 14.4 & 1.2 & 5.8 & 5.2 \\
\hline
\end{tabular}


sumed biomass came from fish, it is the less abundant elements of its diet that were noteworthy. It was the only species with significant fractions of euphausiids (chiefly Stylocheiron) and hyperiids (chiefly Platyscelidae) in its diet. The diet was also unique in the occurrence of alciopid polychaetes, crab megalopae, and a gastropod. Finally, the principal taxon of dietary copepods was Candacia pachydactyla; 1 individual contained 10 pontellid copepods. Both taxa are associated with epipelagic or, in the case of pontellids, neustonic waters. Often, these copepods were whole (or nearly so) suggesting they did not appear in the diet via an intermediate predator such as Stylocheiron. Sternoptyx pseudobscura is known to be a non-migrating member of the deep mesopelagic to bathypelagic community (Baird 1971, Hopkins \& Baird 1985, Kinzer \& Schulz 1988, Hopkins et al. 1997), and the paradox involving its consumption of shallow water prey was noted previously. The occurrence of such taxa in the diet of fish collected within the bathypelagic zone reinforces existing data, but contributes nothing towards explanation.

\section{Resource partitioning}

Previous ecological work in the deep-sea has shown evidence of competition, even within the hadal zone (Blankenship \& Levin 2007). In the Mediterranean, decapods exhibit little dietary overlap between congeners (Cartes 1993a,b), although the amount of dietary overlap was shown to increase with depth (Cartes 1998). Work on micronekton in the eastern Gulf of Mexico examined dietary overlap at a variety of taxonomic levels ranging from intraspecific to community assemblage. Each data set clearly demonstrated resource partitioning both intraspecifically and interspecifically (Flock \& Hopkins 1992, Hopkins \& Gartner 1992, Hopkins et al. 1994, Hopkins et al. 1997, Hopkins \& Sutton 1998). The factors considered for overlap were prey composition, prey size, daytime vertical distribution and nighttime vertical distribution. As in the present study, Hopkins \& Sutton (1998) examined resource partitioning between varieties of the dominant taxonomic groups and found a high degree of resource partitioning between species pairs. Among the 98 cluster units derived from 47 species, $65.4 \%$ overlapped in none of the 3 categories, $22.4 \%$ overlapped in 1 , and $11.2 \%$ overlapped in 2 . Only $1 \%$ of the pairings overlapped in all 3 categories.

Several conditions in the present study decreased the resolution of the data: low taxonomic resolution of prey items due to mastication by decapods, inability to assign meaningful biomass estimates to detrital and cnidarian material, and coarse depth resolution of the bathypelagic samples precluded use of vertical distribution as a niche parameter. The third point is potentially the most problematic given the importance of

Table 5. Dietary overlap between bathypelagic species based on the taxonomic composition and size of prey items

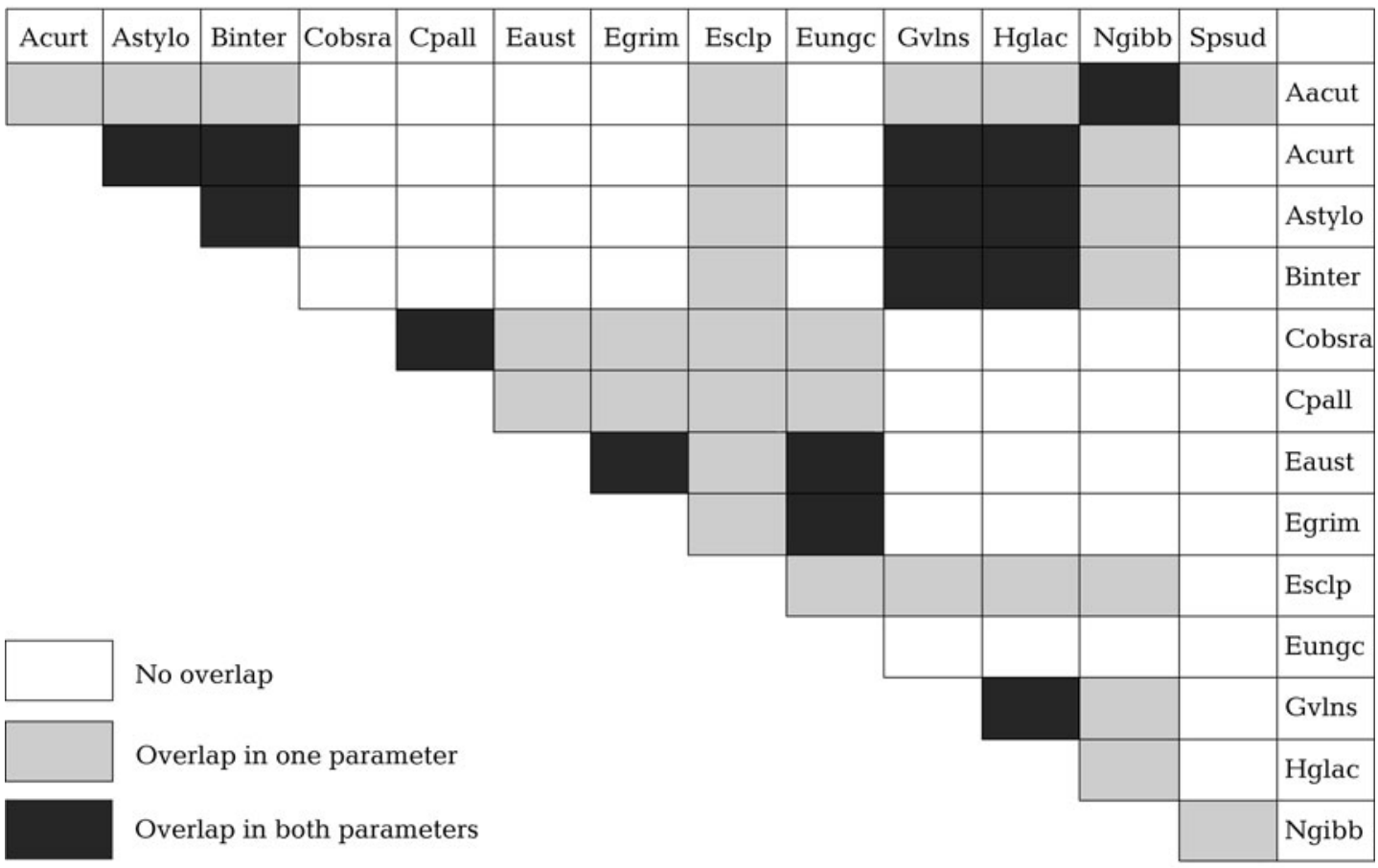


space in defining niche (Schoener 1974). Among mesopelagic decapods and lophogastrids, partitioning of habitat occurred in slightly more of the pairings than did partitioning of food (98\% versus $92 \%$, respectively: Hopkins et al. 1994). Between fish and shrimp species within the same assemblage, analysis produced 26 clusters for habitat, but only 18 for diet composition and 11 for prey size (Hopkins \& Sutton 1998).

Despite not using space as a niche parameter, our results demonstrated niche partitioning similar to that found in the mesopelagic zone, where space was considered. Of the 91 possible species pairings, overlap in both niche parameters was infrequent, occurring in only 15 cases $(16.5 \%)$, while overlap in one parameter occurred in 30 cases $(33.0 \%)$. The most common pattern was a lack of overlap in either category, a situation that occurred in approximately half (46) of the pairings $(50.5 \%)$ (Table 5). Even at gross taxonomic resolution of prey items, niches of bathypelagic micronekton species appear to be partitioned by food, although diet overlap is common within genera. Diets are largely carnivorous with bathypelagic species consuming a higher proportion of fish than their mesopelagic counterparts.

Acknowledgements. This work would not have been possible without the dedication of the Florida Institute of Oceanography, the Louisiana Universities Marine Consortium, the crew of the R/V 'Suncoaster', the crew of the R/V 'Pelican', and the USF Center for Ocean Technology. T. Sutton, J. Donnelly, T. Frank, E. Peebles, A. Remsen, C. Simoniello, S. Geiger and T. Bailey also provided valuable aid. Ship time for this study was provided by the Office of Naval Research award no. N0001496-1-5020, NSF grant OCE 9712572 to J. J. Torres, and by the British Broadcasting Corporation.

\section{LITERATURE CITED}

Baird RC (1971) The systematics, distribution, and zoogeography of the marine hatchetfishes (Family Sternoptychidae). Bull Mus Comp Zool Harvard Univ 142:1-128

Blankenship LE, Levin LA (2007) Extreme food webs: Foraging strategies and diets of scavenging amphipods from the ocean's deepest 5 kilometers. Limnol Oceanogr 52: 1685-1697

Burghart SE (2006) Micronektonic community composition and trophic structure within the bathypelagic zone in the eastern Gulf of Mexico. Dissertation, University of South Florida, Tampa

Burghart SE, Hopkins TL, Torres JJ (2007) The bathypelagic Decapoda, Lophogastrida, and Mysida of the eastern Gulf of Mexico. Mar Biol 152:315-327

Cartes JE (1993a) Feeding-habits of pasiphaeid shrimps close to the bottom on the Western Mediterranean slope. Mar Biol 117:459-468

Cartes JE (1993b) Feeding habits of oplophorid shrimps in the deep western Mediterranean. J Mar Biol Assoc UK 73: 193-206

Cartes JE (1998) Feeding strategies and partition of food resources in deep-water decapod crustaceans (400-2300 m). J Mar Biol Assoc UK 78:509-524
Childress JJ, Nygaard M (1973) The chemical composition of midwater fishes as a function of depth of occurrence off southern California. Deep-Sea Res 20:1093-1109

Childress JJ, Nygaard M (1974) Chemical composition and buoyancy of midwater crustaceans as function of depth of occurrence off Southern California. Mar Biol 27:225-238

Childress JJ, Price MH, Favuzzi J, Cowles D (1990) Chemical composition of midwater fishes as a function of depth of occurrence off the Hawaiian Islands: food availability as a selective factor? Mar Biol 105:235-246

Clarke KR, Gorley RN (2006) PRIMER v6: User manual/tutorial, Plymouth, UK, p 190

Clarke KR, Somerfield PJ, Gorley RN (2008) Testing of null hypotheses in exploratory community analyses: similarity profiles and biota-environment linkage. J Exp Mar Biol Ecol 366:56-69

Donnelly J, Torres JJ (1988) Oxygen consumption of midwater fishes and crustaceans from the eastern Gulf of Mexico. Mar Biol 97:483-494

Fanelli E, Cartes JE, Rumolo P, Sprovieri M (2009) Food-web structure and trophodynamics of mesopelagic-suprabenthic bathyal macrofauna of the Algerian Basin based on stable isotopes of carbon and nitrogen. Deep-Sea Res I 56: $1504-1520$

> Flock ME, Hopkins TL (1992) Species composition, vertical distribution, and food habits of the sergestid shrimp assemblage in the eastern Gulf of Mexico. J Crustac Biol 12:210-223

Gartner JV, Conley WJ, Hopkins TL (1988) Escapement by fishes from midwater trawls: a case study using lanternfishes (Pisces: Myctophidae). Fish Bull 87:213-222

> Heffernan JJ, Hopkins TL (1981) Vertical distribution and feeding of the shrimp genera Gennadas and Bentheogennema (Decapoda: Penaeidea) in the Eastern Gulf of Mexico. J Crustac Biol 1:461-473

> Hopkins TL (1982) The vertical distribution of zooplankton in the eastern Gulf of Mexico. Deep-Sea Res 29:1069-1083

Hopkins TL, Baird RC (1985) Feeding ecology of four Hatchetfishes (Sternoptychidae) in the Eastern Gulf of Mexico. Bull Mar Sci 36:260-277

> Hopkins TL, Gartner JV (1992) Resource-partitioning and predation impact of a low-latitude myctophid community. Mar Biol 114:185-197

Hopkins TL, Sutton TT (1998) Midwater fishes and shrimps as competitors and resource partitioning in low latitude oligotrophic ecosystems. Mar Ecol Prog Ser 164:37-45

> Hopkins TL, Flock ME, Gartner JV, Torres JJ (1994) Structure and trophic ecology of a low latitude midwater decapod and mysid assemblage. Mar Ecol Prog Ser 109:143-156

> Hopkins TL, Sutton TT, Lancraft TM (1996) The trophic structure and predation impact of a low latitude midwater fish assemblage. Prog Oceanogr 38:205-239

Hutchinson G (1961) Paradox of plankton. Am Nat 95: 137-145

Kinsey ST, Hopkins TL (1994) Trophic strategies of euphausiids in a low-latitude ecosystem. Mar Biol 118:651-661

- Kinzer J, Schulz K (1988) Vertical distribution and feeding patterns of midwater fish in the central equatorial Atlantic II. Sternoptychidae. Mar Biol 99:261-269

Mauchline J, Gordon JDM (1985) Trophic diversity in deepsea fish. J Fish Biol 26:527-535

Mauchline J, Gordon JDM (1986) Foraging strategies of deep-sea fish. Mar Ecol Prog Ser 27:227-238

Nielson JG (1984) Nemichthyidae. In: Whitehead PJP, Bauchot ML, Hureau JC, Nielson J, Tortonese E (eds) Fishes of the North-eastern Atlantic and the Mediterranean, Vol 2. UNESCO, Paris, p 551-554 
Polunin NVC, Morales-Nin B, Pawsey WE, Cartes JE, Pinnegar JK, Moranta J (2001) Feeding relationships in Mediterranean bathyal assemblages elucidated by stable nitrogen and carbon isotope data. Mar Ecol Prog Ser 220: 13-23

Roe HSJ (1984) The diel migrations and distributions within a mesopelagic community in the north east Atlantic. 2. Vertical migrations and feeding of mysids and decapod crustacea. Prog Oceanogr 13:269-318

Schoener TW (1974) Resource partitioning in ecological communities. Science 185:27-39

Editorial responsibility: Hans Heinrich Janssen, Oldendorf/Luhe, Germany
Stickney DG, Torres JJ (1989) Proximate composition and energy content of mesopelagic fishes from the eastern Gulf of Mexico. Mar Biol 103:13-24

Sutton TT, Hopkins TL (1996a) Trophic ecology of the stomiid (Pisces: Stomiidae) assemblage of the eastern Gulf of Mexico: strategies, selectivity and impact of a mesopelagic top predator group. Mar Biol 127:179-192

Sutton TT, Hopkins TL (1996b) The species composition, abundance, and vertical distribution of the stomiid (Pisces: Stomiiformes) fish assemblage of the Gulf of Mexico. Bull Mar Sci 59:530-542

Submitted: May 2, 2009; Accepted: October 8, 2009 Proofs received from author(s): January 21, 2010 